\title{
Predictive Value of Neutrophil-to-Lymphocyte Ratio in Outcomes of Patients with Acute Coronary Syndrome
}

\author{
Wassam Eldin Hadad El Shafey ${ }^{{ }^{*},}$ Ahmed Mohamed Emara1, Walaa Farid Mosa1, \\ Khaled Hussein El-Sharnouby ${ }^{2}$ \\ ${ }^{1}$ Department of Cardiology, Menoufia University Hospitals, Menoufia, Egypt \\ ${ }^{2}$ Department of Cardiology, Shibin El Kom Teaching Hospital, Menoufia, Egypt

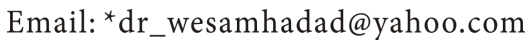

How to cite this paper: El Shafey, W.E.H., Emara, A.M., Mosa, W.F. and El-Sharnouby, K.H. (2018) Predictive Value of Neutrophil-to-Lymphocyte Ratio in Outcomes of Patients with Acute Coronary Syndrome. World Journal of Cardiovascular Diseases, 8, 265-275.

https://doi.org/10.4236/wjcd.2018.85026

Received: April 2, 2018

Accepted: May 25, 2018

Published: May 28, 2018

Copyright $\odot 2018$ by authors and Scientific Research Publishing Inc. This work is licensed under the Creative Commons Attribution International License (CC BY 4.0).

http://creativecommons.org/licenses/by/4.0/

\begin{abstract}
Objectives: Previous studies have demonstrated the role of inflammation in acute coronary syndrome (ACS). The neutrophil-to-lymphocyte ratio (NLR) was found to be a useful inflammatory marker for predicting adverse outcomes. We hypothesized that an elevated neutrophil-to-lymphocyte ratio would be associated with increased mortality in patients with acute coronary syndrome. Methods: The study consisted of 40 patients with acute coronary syndrome who were admitted to Cardiology Department-Menoufia University Hospitals. The primary endpoint was all-cause in-hospital as well as 30-day mortality, and the patients were divided into three tertiles according to their admission NLR results. Results: All-cause 30-day mortality in the three groups based on NLR was $0.0 \%, 7.7 \%$ and $28.6 \%$, in the low-, middle- and high-NLR groups, respectively ( $\mathrm{P}<0.05 ; \chi^{2}$ test). In a logistic regression analysis, including baseline demographic, clinical, and biochemical covariates, the neutrophil-to-lymphocyte ratio was an independent predictor of mortality $(\mathrm{OR}=2.44,95 \% \mathrm{CI}=1.185-5.007, \mathrm{P}<0.05)$. Conclusion: An elevated neutrophil-to-lymphocyte ratio (NLR), a simple, relatively inexpensive and universally available inflammatory marker, seems to be a predictor of 30-day mortality in patients with acute coronary syndrome.
\end{abstract}

\section{Keywords}

Acute Coronary Syndrome, Inflammation, Ischemia,

Neutrophil-to-Lymphocyte Ratio, Mortality

\section{Introduction}

Many factors including diabetes, hypertension, smoking and dyslipidemia, all of 
which contribute to endothelial injury is the basis of the pathogenesis of atherosclerosis. Along with other risk factors like genetic predisposition, they can lead to the development of this syndrome [1] [2]. It's now supported by sufficient evidence that atherosclerosis represents an active inflammation and it's way more than just an infiltration of lipids in the affected vessel wall [2] [3] [4].

Acute coronary syndrome (ACS) represents a spectrum of clinical symptoms compatible with acute myocardial ischemia and it ranges from unstable angina (UA) to non-ST-segment elevation myocardial infarction (NSTEMI) to ST-segment elevation myocardial infarction (STEMI). UA and NSTEMI are closely related conditions: their pathophysiologic origins and clinical presentations are similar, but they differ in severity [5].

White blood cells (WBC) play a key role in this active process and numerous studies reported a relationship between leucocytes and the severity of coronary artery disease (CAD) as well as the development of acute coronary syndrome [3] [4] [5] [6]. It is believed that mononuclear cells (monocytes, macrophages, $\mathrm{T}$ lymphocytes), which are prevalent, may play a pathogenic role in unstable coronary artery plaques [1] [2] [4]. Also neutrophil is thought to be a major element in the healing process post-MI as well as the reperfusion injury in the settings of ACS [7] [8] [9] [10]. Elevated total leucocytic count (TLC) had been linked to increased short- and long-term incidence of major acute cardiovascular events (MACE) as well as death in several previous studies [11] [12] [13].

Many inflammatory biomarkers had been put under study to investigate their predictive value in predicting MACE and death after ACS, and it was found that NLR has a promising predictive power among those biomarkers [14].

\section{Methods}

\subsection{Study Design}

This is a prospective observational study that included consecutive adult patients $>18$ years of age admitted to Cardiology Department-Menoufia University Hospitals with ACS in order to study the relationship between neutrophil-to-lymphocyte ratio at time of admission and in-hospital as well as 30-day mortality. This study included 40 patients.

\subsection{Definitions}

ACS was defined as any group of clinical symptoms compatible with acute myocardial ischemia and covers the spectrum of clinical conditions ranging from unstable angina (UA) to non-ST-segment elevation myocardial infarction (NSTEMI) to ST-segment elevation myocardial infarction (STEMI) [5]. Based on the electrocardiogram (ECG), two groups of patients should be differentiated: 1) Patients with acute chest pain and persistent ( $>20 \mathrm{~min}$ ) ST-segment elevation. This condition is termed ST-elevation ACS and generally reflects an acute total coronary occlusion. 2) Patients with acute chest pain but no persistent ST-segment elevation. ECG changes may include transient ST-segment eleva- 
tion, persistent or transient ST-segment depression, T-wave inversion, flat $\mathrm{T}$ waves or pseudo-normalization of $\mathrm{T}$ waves or the ECG may be normal [15]. Unstable angina is defined as myocardial ischaemia at rest or minimal exertion in the absence of cardiomyocyte necrosis [15].

\subsection{Study Population}

All patients $>18$ years of age admitted with ACS and not having any of the exclusion criteria were included in the study. Exclusion criteria were essentially based on conditions which can alter total or differential leucocytic counts. So, patients with history of trauma, surgery, neoplasm, or infectious disease 30-day before admission were excluded from our study. We also excluded patients with history of current use of immunosuppressant (including corticosteroids) and patients with post-admission complications such as cardiogenic shock, serious arrhythmias with hemodynamic instability, or heart failure. All patients were subjected to informed consent, thorough history taking and clinical examination, 12 lead surface ECG. They were also subjected to routine laboratory analysis with special concern to complete blood count (CBC), and biochemical measurements of myocardial necrosis markers. The blood samples to assess neutrophilic count, lymphocytic count and neutrophil-to-lymphocyte ratio (NLR) were collected within 1 hour after admission to the hospital. Patients were categorized into tertiles (three groups) on the basis of their admission NLR values, as low, intermediate, and high NLR groups. Echocardiography was performed for each patient in the coronary care unit. All data were analyzed, at least 3 cardiac cycles for each parameter and the average results were obtained. We measured left ventricular end diastolic diameter (LVEDD), left ventricular end systolic diameter (LVESD) and Ejection fraction (EF): calculated by modified Simpson's method. The hospitalization period for every patient was recorded. Correlation between level of NLR and in-hospital as well as 30-day mortality was done.

\subsection{Statistical Analysis}

Statistical analyses were performed using the SPSS software version 22.0 (SPSS Inc, Illinois). Patient demographic characteristics were presented as mean and standard deviation for continuous variables with normal distribution, median and interquartile range for continuous variables with non-normal distributions and as proportions (percentages) for categorical variables. For continuous variables comparison between the three population subgroups was done by One-way ANOVA test, followed by Post Hoc (Tukey) test whenever significant difference is found. Simple two- or three-group comparisons were performed using $\chi^{2}$ (Chi-square) test for categorical variables. Pearson's correlation and simple linear regression were conducted between patients' admission EF as a dependent variable and their admission NLR as an independent variable. Also logistic regression analyses were performed to assess the respective independent effects of several variables on 30-day mortality. Odds ratios (ORs) and corres- 
ponding 95\% confidence intervals (CIs) are reported for covariates of statistical significance. We used Kaplan-Meier survival analysis, to assess 30-day mortality outcome in relation to NLR tertiles. The Receiver Operating Characteristics (ROC) curve was used to demonstrate the sensitivity and specificity of NLR and its respective optimal cutoff value for predicting mortality outcome. The confidence interval was set to $95 \%$ and the margin of error accepted was set to $5 \%$. So a $P$ value lower than 0.05 was considered significant.

\section{Results}

The study population consisted of 40 consecutive patients with ACS. In all, $67.5 \%$ of the patients were male, and mean age of patients was $63.3 \pm 5.42$ years. In all, 22 (55\%) patients were hypertensive, 22 (55\%) patients were diabetic, 24 $(60 \%)$ patients were hyperlipidemic, and 20 (50\%) patients were smokers. 8 (20\%) patients were diagnosed as UA, 22 (55\%) as NSTEMI and $10(25 \%)$ as STEMI. Mean admission laboratory results was $10.33 \pm 2.34\left(\times 10^{9} / \mathrm{L}\right)$ for TLC, while it was $6.28(5.27,8.49) \times 10^{9} / \mathrm{L}$ for absolute neutrophilic $(\mathrm{N})$ count, $1.69(1$, 2.23) $\times 10^{9} / \mathrm{L}$ for absolute lymphocytic (L) count and $3.76(2.3,8.56)$ for NLR. Figure 1 shows distribution of NLR results among study population. Mean LV EF was $48.65 \pm 10.85$. The total number of patients died within 30 -day of admission was $5(12.5 \%), 2$ (5\%) of them died during the in-hospital period.

Table 1 shows that there was no statistically significant difference between the three studied groups as regard to age, sex, and risk factors $(P>0.05)$. It also shows that there were statistically significant differences between the three studied groups regarding $\mathrm{N}$ count, $\mathrm{L}$ count and TLC. Post Hoc analysis revealed

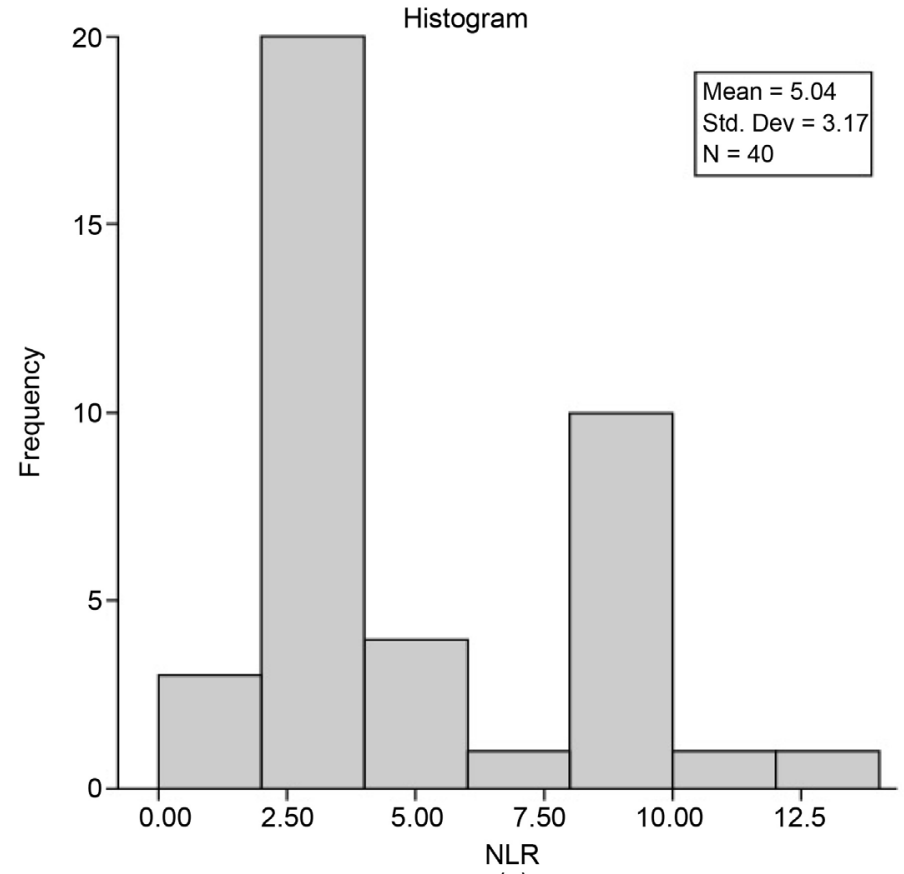

(a)

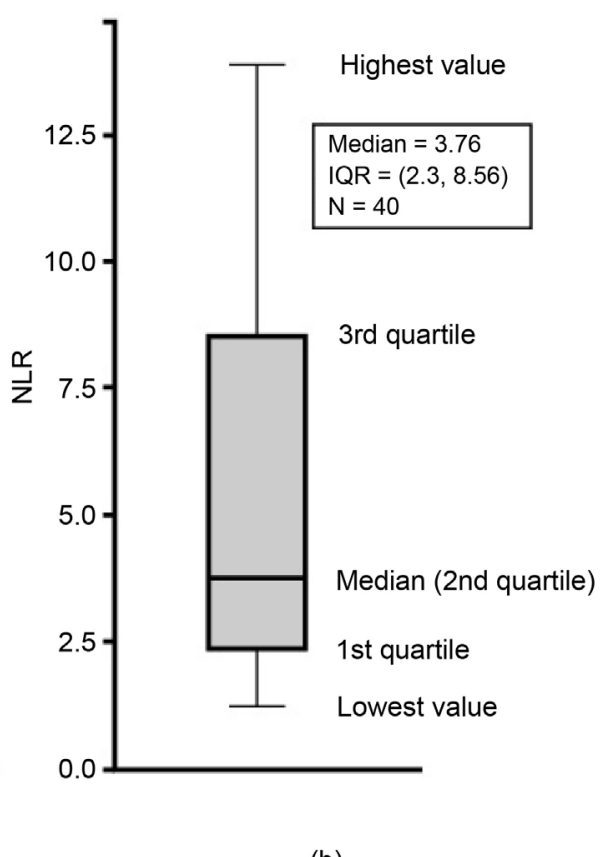

(b)

Figure 1. Histogram and box plot showing distribution of NLR among study population. 
Table 1. Demographic, clinical, laboratory, echocardiographic and other data comparison between study groups.

\begin{tabular}{|c|c|c|c|c|}
\hline Variable & $\begin{array}{c}\text { Low } \operatorname{NLR}(<3) \\
\text { n: } 13\end{array}$ & $\begin{array}{c}\text { Intermediate NLR } \\
\qquad \begin{array}{c}(3-4.7) \\
\mathrm{n}: 13\end{array}\end{array}$ & $\begin{array}{c}\text { High NLR (>4.7) } \\
\text { n: } 14\end{array}$ & $\mathrm{P}$ \\
\hline Age, years & $60.9 \pm 4.1$ & $63.6 \pm 2.5$ & $65.2 \pm 7.5$ & 0.115 \\
\hline Men, n (\%) & $8(61.5 \%)$ & $8(61.5 \%)$ & $11(78.6 \%)$ & 0.548 \\
\hline HTN, n (\%) & $5(38.5 \%)$ & $8(61.5 \%)$ & $9(64.3 \%)$ & 0.341 \\
\hline $\mathrm{DM}, \mathrm{n}(\%)$ & $5(38.5 \%)$ & $9(69.2 \%)$ & $8(57.1 \%)$ & 0.283 \\
\hline HPL, n (\%) & $9(69.2 \%)$ & $8(61.5 \%)$ & $7(50 \%)$ & 0.589 \\
\hline Smoker, n (\%) & $5(38.5 \%)$ & $7(53.8 \%)$ & $8(57.1 \%)$ & 0.59 \\
\hline TLC, $\left(\times 10^{9} / \mathrm{L}\right)$ & $8.7 \pm 1.5$ & $10.2 \pm 1.8$ & $12 \pm 2.4$ & $<0.001$ \\
\hline $\mathrm{N}$ count, $\left(\times 10^{9} / \mathrm{L}\right)$ & $4.9 \pm 0.81$ & $6.6 \pm 1$ & $8.9 \pm 1.9$ & $<0.001$ \\
\hline $\mathrm{L}$ count, $\left(\times 10^{9} / \mathrm{L}\right)$ & $2.3 \pm 0.16$ & $1.7 \pm 0.16$ & $1.0 \pm 0.14$ & $<0.001$ \\
\hline $\mathrm{EF}, \%$ & $55.4 \pm 8.3$ & $49.5 \pm 8.8$ & $41.6 \pm 10.9$ & $<0.01$ \\
\hline \multicolumn{5}{|l|}{ ACS type, n (\%) } \\
\hline UA & $6(46.2 \%)$ & $2(15.4 \%)$ & $0(0.0 \%)$ & \\
\hline NSTEMI & $6(46.2 \%)$ & $8(61.5 \%)$ & $8(57.1 \%)$ & $<0.05$ \\
\hline STEMI & $1(7.6 \%)$ & $3(23.1 \%)$ & $6(42.9 \%)$ & \\
\hline \multicolumn{5}{|l|}{ Mortality, n (\%) } \\
\hline In-hospital & $0(0.0 \%)$ & $0(0.0 \%)$ & $2(14.3 \%)$ & 0.142 \\
\hline 30-day & $0(0.0 \%)$ & $1(7.7 \%)$ & $4(28.6 \%)$ & $<0.05$ \\
\hline
\end{tabular}

Abbreviations: HTN, hypertension; DM, diabetes mellitus; HPL, hyperlipidemia; TLC, total leucocytic count; N count, neutrophilic count; L count, lymphocytic count; NLR, neutrophil-to-lymphocyte ratio; EF, ejection fraction; ACS, acute coronary syndrome; UA, unstable angina; NSTEMI, non-ST elevation myocardial infarction; STEMI, ST elevation myocardial infarction. Data are expressed as mean \pm SD, or number (percentage).

statically significant difference as regard to TLC between groups III \& I $(\mathrm{P}<$ 0.001). While there was no significant difference between group II and any of either Group I or III. While as regard N and L counts, both revealed highly statistically significant difference between any two of the three groups of study population $(\mathrm{P}<0.001)$. There was statistically significant difference between the three studied groups regarding LV systolic function with $\mathrm{P}$-value $<0.05$, which on Post Hoc analysis revealed statically significant difference between groups III \& I $(\mathrm{P}<0.05)$. While there was no significant difference between group II and any of either Group I or III. A simple linear regression was conducted to predict patients' EF based on their NLR values. A significant regression equation was found $(\mathrm{F}(1,38)=26.412, \mathrm{P}<0.001)$, with an $\mathrm{R}^{2}$ of 0.410 . It elaborated that patients' average EF decreased by 2.195 unit (i.e. \%) for each unit increase of NLR. It's also shown that there was a statistically significant difference between the three studied groups regarding the type of ACS with a P-value $<0.05$. Concerning mortality outcome there was a statistically significant difference found between the three studied groups regarding 30-day mortality outcome with a $\mathrm{P}$-value $<0.05$. On comparison between each two groups as regard 30-day mor- 
tality outcome, the statistically significant difference was only found between group I and III with a P-value $<0.05$. On the other hand there wasn't a statistically significant difference between the study groups as regard in-hospital mortality.

In Kaplan-Meier survival analysis, the 30 -day mortality rate was $28.6 \%$ in the high-NLR group versus $7.7 \% \& 0.0 \%$ in the intermediate $\&$ low-NLR groups respectively, with a statistical significant gradient between groups I \& III with a P-value $<0.05$ (Figure 2). Also in ROC curve analysis, we explored the relation between admission NLR and 30-day mortality outcome. An NLR value of "9" was identified as an effective cut-off point with an AUC (Area under Curve) = 0.926 making the test classified as an excellent prognostic marker (AUC > 0.9) and a P-value $<0.05$. An NLR value $\geq 9$ yielded a sensitivity of $80 \%$, a specificity of $91.34 \%$, a positive predictive value of $57.14 \%$, a negative predictive value of $97 \%$ and an accuracy of $90 \%$ (Figure 3 ). Of the 40 patients enrolled in the study, only 7 patients whose NLR results were $\geq 9$. Their descriptive statistics were as follows. Regarding categorical variables, 5 patients were male, 4 patients were hypertensive, 5 patients were diabetic, 3 patients were smokers, 4 were diagnosed as STEMI, 3 were diagnosed as Non-STEMI, but none of them was diagnosed as UA. 5 patients died during 30-dayfollow up period. The median and interquartile range of each of the following continues variables were as follows; age was $70(60,70)$ years, EF was $32(27,43) \%$, TLC was $14(12.5,14.5) \times 10^{9} / \mathrm{L}$,

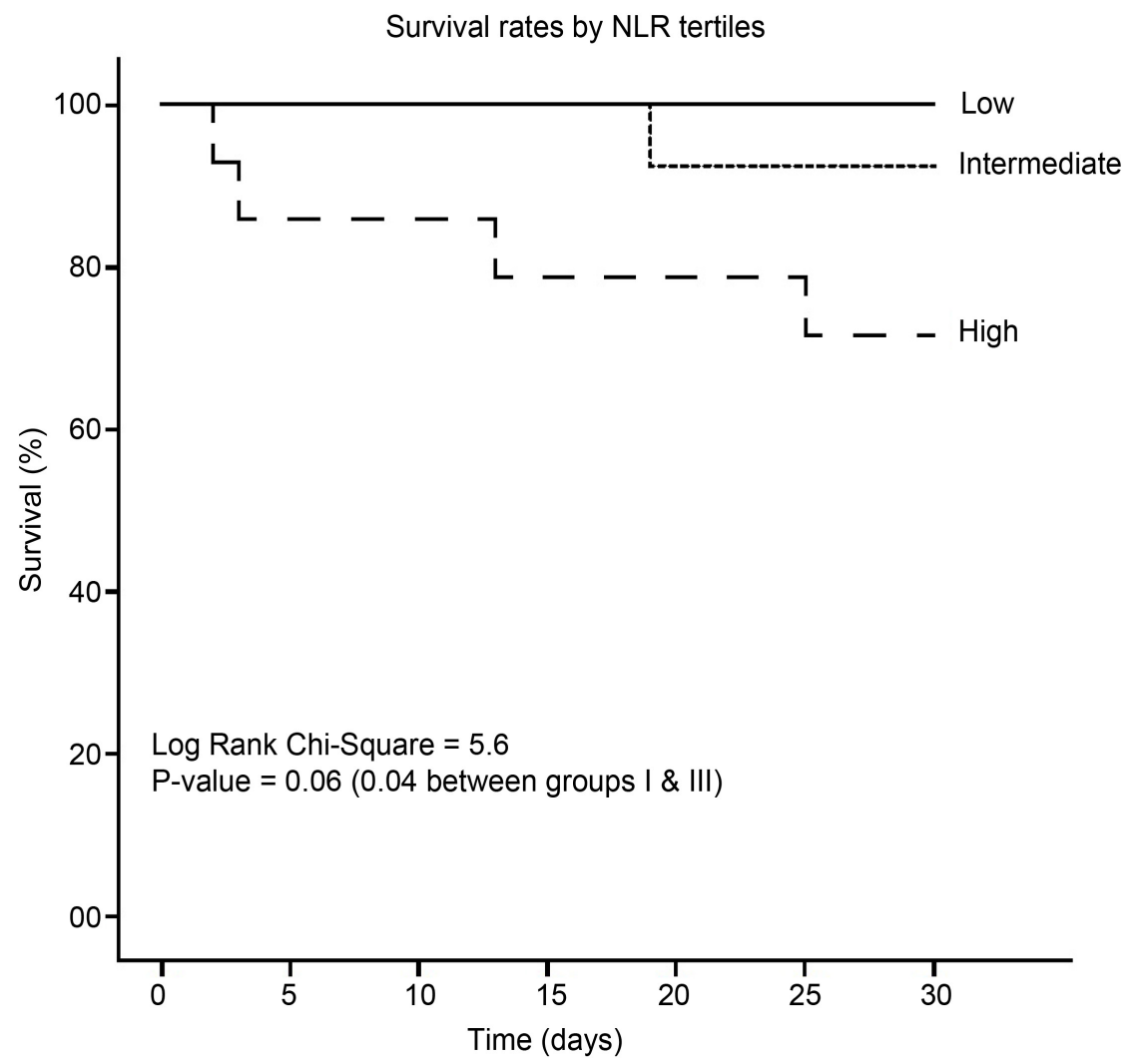

Figure 2. Kaplan-Meier curve for 30-day mortality showing survival rates by NLR tertiles. 


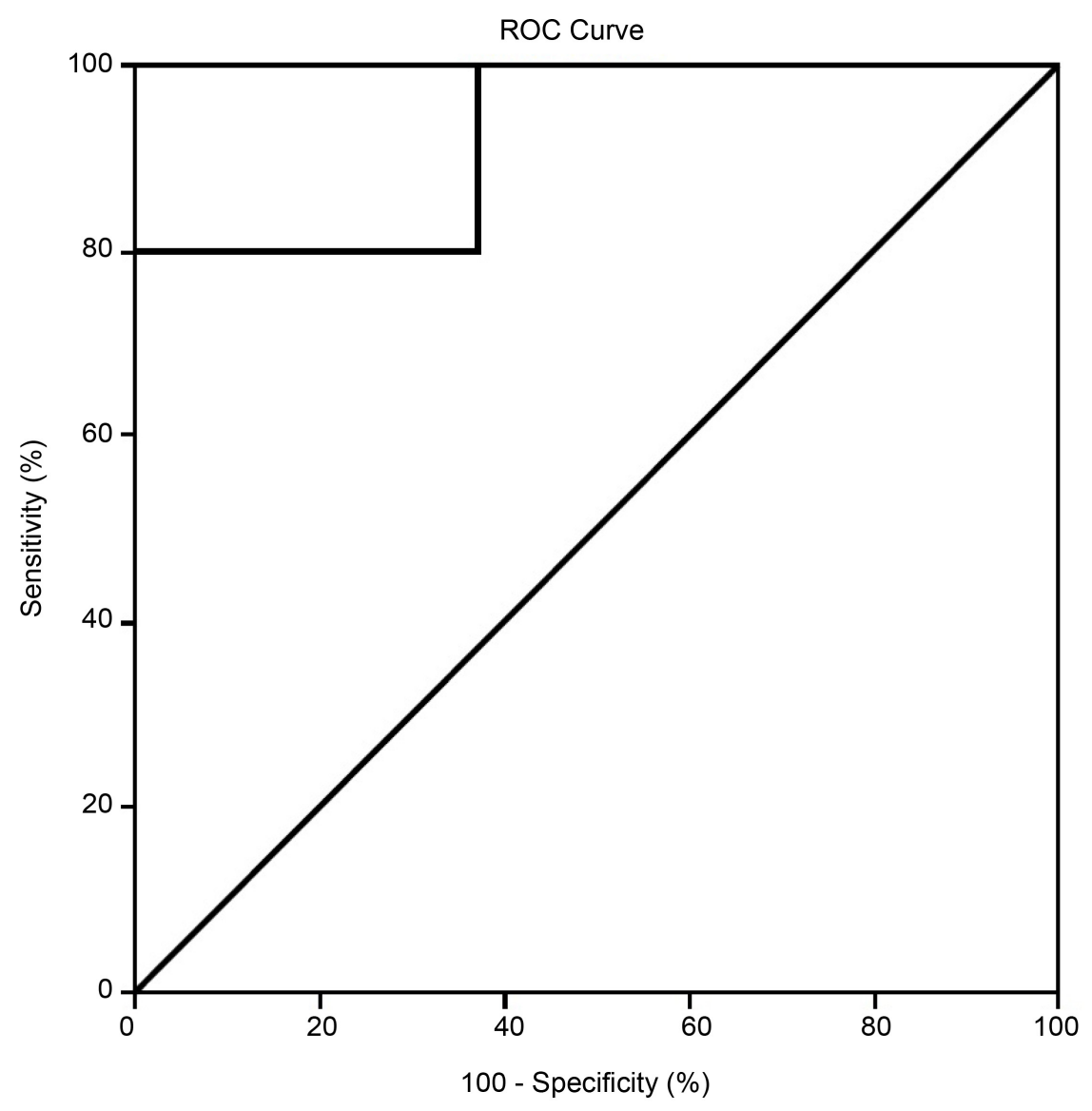

Figure 3. ROC curve analysis.

$\mathrm{N}$ count was $9(8.8,12.1) \times 10^{9} / \mathrm{L}$, L count was $0.95(0.94,1.1) \times 10^{9} / \mathrm{L}, \mathrm{NLR}$ was $9.4(9.1,10.1)$.

A univariate binary logistic regression was conducted using 30-day mortality outcome as a dependent variable and each of the following as an independent variable; age, gender, HTN, DM, smoking, dyslipidemia, admission lab results, EF and ACS type. All covariates showed non-significant results except for absolute $\mathrm{N}$ count and NLR. It showed that NLR is an independent predictor of 30-day mortality with $\mathrm{P}$-value $<0.05(\mathrm{OR}=2.44 \& 95 \% \mathrm{CI}=[1.185-5.007])$ (Table 2).

\section{Discussion}

The major finding of our study is that NLR is an independent predictor of 30-day mortality in patients with ACS. The results of our study regarding the age showed that there was no statistically significant value between the older age and NLR which was also manifest in a previous study [16], while on the other hand some other previous studies found that patients with higher NLR were significantly older than those with lower NLR [13] [17]. In our study we found no significant association between gender and NLR which is in accordance with several previous studies [16] [17] [18] [19]. Also a non-significant association was 
Table 2. Results of univariate binary logistic regression including variables of statistically significant results (NLR values and absolute $\mathrm{N}$ count) ${ }^{*}$.

\begin{tabular}{cccc}
\hline Variable & OR & $95 \% \mathrm{CI}$ & $\mathrm{P}$ \\
\hline $\mathrm{N}$ count $\left(\times 10^{9} / \mathrm{L}\right):$ & 1.76 & $1.093-2.839$ & $<0.05$ \\
$\mathrm{NLR}:$ & 2.44 & $1.185-5.007$ & $<0.05$ \\
\hline
\end{tabular}

${ }^{*}$ Multivariate regression including both variables together couldn't be conducted due to expected multicollinearity as a result of existing significant correlation between both variables. Abbreviations: NLR, neutrophil-to-lymphocyte ratio; $\mathrm{N}$ count, neutrophilic count; OR, odds ratio; $\mathrm{CI}$, confidence interval.

observed between DM and NLR in several previous studies which is concordant to our results [17] [18] [19]. On the other hand our results regarding DM are discordant to what was observed in several studies [13] [16] [20]. As to HTN our results are concordant with the results of numerous previous studies, all of which found no significant association between HTN and NLR [13] [16] [17] [18] [19]. In relation to dyslipidemia our results are in accordance with the results obtained from several previous studies [16] [17] [18] [19]. While a larger study reported a highly statistical significant difference regarding the prevalence of dyslipidemia among study groups [13]. The results of our study regarding smoking are concordant with what was found in a number of previous studies [16] [17] [19]. But this was not the case in a previous study conducted on Non-STEACS patients [18]. According to the previously mentioned results in our study, it seems that NLR is an independent factor that is not affected by other cardiac risk factors like age, sex hypertension, diabetes mellitus, dyslipidemia and smoking. Differences of the above data in the three groups were not statistically significant $(\mathrm{P}>0.05)$ in our study.

Moving to admission lab findings, we found a significant association between TLC and NLR which was also the case in a number of previous studies [13] [16] [18] [19]. Also, results of our study regarding neutrophilic and lymphocytic counts are concordant with the results found in other studies [13] [16] [19].

With reference to LV EF, our study results are in accordance with the results of several previous studies [18] [20] [21].

In our study we found the distribution of ACS type among the population of the study groups was significantly different which is concordant to what was observed in a previous study, but discordant to another one [13] [17]. Such finding may indicate the presence of a diagnostic role of NLR in patients of ACS that requires further evaluation in larger future studies.

Finally, in relation to mortality outcome, our study results as regard to in-hospital mortality aren't in the same line with results observed in several previous studies, all of which showed highly statistical significant difference between the study groups in relation to in-hospital mortality [13] [17] [19] [20]. But on the other hand, a previous study showed results concordant to ours regarding in-hospital mortality $(\mathrm{P}>0.05)$ [18]. Such discordance in results may be attributed to the small sample size of our study. Additionally, our study results regarding 30-day mortality is concordant to what was found in previous studies, 
one of those studies was conducted on a longer duration of follow up, which was 6 months [13] [16] [17] [18].

\section{Study Limitations}

Although the number of patients enrolled in our study is relatively small, the results are quite comparable to larger studies. Duration of ACS symptoms may have an important impact on NLR levels but was not addressed in current study. A longer-term (more than one month) of follow up may be needed for more comprehensive assessment of relationship between NLR and long-term mortality outcome. Additionally, we could not compare NLR with other inflammatory markers, such as C-reactive protein, fibrinogen, myeloperoxidase, tumor necrosis factor- $\alpha$ or interleukin (IL)-6, because they were not routinely obtained in our study population. Finally, this study was observational and single-institutional in nature, which possibly restricted us from identifying and analyzing all potential confounding factors.

\section{Conclusion}

Based on the results of the current study, it can be concluded that NLR, a simple, relatively inexpensive and universally available inflammatory marker, is an independent predictor of 30-day mortality and can provide an additional level of risk stratification in patients diagnosed with ACS. Further studies in larger cohorts are needed for the validation of these findings to better define the role of NLR in clinical decision making in patients with ACS.

\section{Acknowledgements}

I'd like to thank my thesis advisor Dr. Ahmed Emara, Prof. of Cardiology at Menoufia University. The door to Prof. Emara's office was always open whenever I ran into a trouble spot or had a question about my research or writing. $\mathrm{He}$ consistently allowed this paper to be my own work, but steered me in the right the direction whenever he thought I needed it.

\section{Declaration of Conflicting Interests}

The author(s) declared no potential conflicts of interest with respect to the research, authorship, and/or publication of this article.

\section{Funding}

The author(s) received no financial support for the research, authorship, and/or publication of this article.

\section{References}

[1] Libby, P. (2003) Vascular Biology of Atherosclerosis: Overview and State of the Art. American Journal of Cardiology, 91, 3-6.

https://doi.org/10.1016/S0002-9149(02)03143-0 
[2] Ross, R. (1999) Atherosclerosis-An Inflammatory Disease. New England Journal of Medicine, 340, 115-126. https://doi.org/10.1056/NEJM199901143400207

[3] Falk, E., Shah, P. and Fuster, V. (1995) Coronary Plaque Disruption. Circulation, 192, 657-671. https://doi.org/10.1161/01.CIR.92.3.657

[4] Libby, P. (1995) Molecular Basis of the Acute Coronary Syndromes. Circulation, 91, 2844-2852. https://doi.org/10.1161/01.CIR.91.11.2844

[5] Kumar, A. and Cannon, C.P. (2209) Acute Coronary Syndromes: Diagnosis and Management, Part I. Mayo Clinic Proceedings, 84, 917-938. https://doi.org/10.4065/84.10.917

[6] Hoffman, M., Blum, A., Baruch, R., Kaplan, E. and Benjamin, M. (2004) Leukocytes and Coronary Heart Disease. Atherosclerosis, 172, 1-6. https://doi.org/10.1016/S0021-9150(03)00164-3

[7] Maxwell, S.R.J. and Lip, G.Y.H. (1997) Reperfusion Injury: Review of the Pathophysiology, Clinical Manifestations and Therapeutic Options. Journal of Cardiology, 58, 95-117. https://doi.org/10.1016/S0167-5273(96)02854-9

[8] Ott, I., Neumann, F.J., Gawaz, M., Schmitt, M. and Schömig, A. (1996) Increased Neutrophil-Platelet Adhesion in Patients with Unstable Angina. Circulation, 94, 1239-1246. https://doi.org/10.1161/01.CIR.94.6.1239

[9] Pearson, T.A., Mensah, G.A., Alexander, R.W., et al. (2003) Markers of Inflammation and Cardiovascular Disease. Application to Clinical and Public Health Practice: A Statement for Healthcare Professionals from the Centers for Disease Control and Prevention and the American Heart Association. Circulation, 107, 499-511. https://doi.org/10.1161/01.CIR.0000052939.59093.45

[10] Sarma, J., Laan, C.A., Alam, S., Jha, A., Fox, K.A. and Dransfield, I. (2002) Increased Platelet Binding to Circulating Monocytes in Acute Coronary Syndromes. Circulation, 105, 2166-2171. https://doi.org/10.1161/01.CIR.0000015700.27754.6F

[11] Barron, H.V., Cannon, C.P., Murphy, S.A., Braunwald, E. and Gibson, C.M. (2002) Association between White Blood Cell Count, Epicardial Blood Flow, Myocardial Perfusion, and Clinical Outcomes in the Setting of Acute Myocardial Infarction: A Thrombolysis in Myocardial Infarction 10 Substudy. Circulation, 102, 2329-2334. https://doi.org/10.1161/01.CIR.102.19.2329

[12] Pelizzon, G., Dixon, S., Stone, G., et al. (2003) Relation of Admission White Blood Cell Count to Long-Term Outcomes after Primary Coronary Angioplasty for Acute Myocardial Infarction. American Journal of Cardiology, 91, 729-731. https://doi.org/10.1016/S0002-9149(02)03416-1

[13] Tamhane, U.U., Aneja, S., Montgomery, D., Rogers, E.K., Eagle, K.A. and Gurm, H.S. (2008) Association between Admission Neutrophil to Lymphocyte Ratio and Outcomes in Patients with Acute Coronary Syndrome. American Journal of Cardiology, 102, 653-657. https://doi.org/10.1016/j.amjcard.2008.05.006

[14] Horne, B.D., Anderson, J.L., John, J.M., et al. (2005) Intermountain Heart Collaborative Study Group. Which White Blood Cell Subtypes Predict Increased Cardiovascular Risk? Journal of the American College of Cardiology, 45, 1638-1643. https://doi.org/10.1016/j.jacc.2005.02.054

[15] Roffi, M., Patrono, C., Collet, J.P., et al. (2016) 2015 ESC Guidelines for the Management of Acute Coronary Syndromes in Patients Presenting without Persistent ST-Segment Elevation: Task Force for the Management of Acute Coronary Syndromes in Patients Presenting without Persistent ST-Segment Elevation of the European Society of Cardiology (ESC). European Heart Journal, 37, 267-315.

https://doi.org/10.1093/eurheartj/ehv320 
[16] Muhmmed Suliman, M.A., Bahnacy Juma, A.A., Ali Almadhani, A.A., Pathare, A.V., Alkindi, S.S. and Uwe Werner, F. (2010) Predictive Value of Neutrophil to Lymphocyte Ratio in Outcomes of Patients with Acute Coronary Syndrome. Archives of Medical Research, 41, 618-622. https://doi.org/10.1016/j.arcmed.2010.11.006

[17] Bajari, R. and Tak, S. (2017) Predictive Prognostic Value of Neutrophil-Lymphocytes Ratio in Acute Coronary Syndrome. Indian Heart Journal, 69, S46-S50. https://doi.org/10.1016/j.ihj.2017.01.020

[18] Gul, M., Uyarel, H., Ergelen, M., Ugur, M., Isık, T., Ayhan, E., Turkkan, C., Aksu, H.U., Akgul, O. and Uslu, N. (2014) Predictive Value of Neutrophil to Lymphocyte Ratio in Clinical Outcomes of Non-ST Elevation Myocardial Infarction and Unstable Angina Pectoris: A 3-Year Follow-Up. Clinical and Applied Thrombosis/Hemostasis, 20, 378-384. https://doi.org/10.1177/1076029612465669

[19] Soylu, K., Gedikli, Ö., Dagasan, G., et al. (2015) Neutrophil-to-Lymphocyte Ratio Predicts Coronaryartery Lesion Complexity and Mortality after Non-ST-Segment Elevation Acute Coronary Syndrome. Revista Portuguesa de Cardiologia, 34, 465-471. https://doi.org/10.1016/j.repc.2015.01.013

[20] Gazi, E., Bayram, B., Gazi, S., et al. (2015) Prognostic Value of the Neutrophil-Lymphocyte Ratio in Patients with ST-Elevated Acute Myocardial Infarction. Clinical and Applied Thrombosis/Hemostasis, 21, 155-159. https://doi.org/10.1177/1076029613492011

[21] Bekler, A., Erbag, G., Sen, H., Gazi, E. and Ozcan, S. (2015) Predictive Value of Elevated Neutrophil-Lymphocyte Ratio for Left Ventricular Systolic Dysfunction in Patients with Non ST-Elevated Acute Coronary Syndrome. Pakistan Journal of Medical Sciences, 31, 159-163. 